\title{
How Project-Based Organizations Cultivate Learning in Projects: A Social-Constructivist Perspective
}

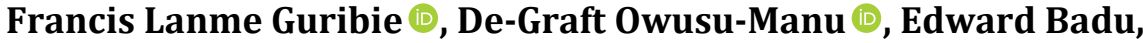 \\ Andrew Victor Kabenlah Jnr Blay
}

Department of Construction Technology and Management, Kwame Nkrumah University of Science and Technology, Kumasi, Ghana Email:2fgrubie@gmail.com, d.owusumanu@gmail.com, edwardbadu@yahoo.com, blayjnr1979@gmail.com

How to cite this paper: Guribie, F.L., Owusu-Manu, D., Badu, E. and Blay, A.V.K.J. (2021) How Project-Based Organizations Cultivate Learning in Projects: A Social-Constructivist Perspective. Journal of Building Construction and Planning Research, 9, 251-271.

https://doi.org/10.4236/jbcpr.2021.94016

Received: August 25, 2021

Accepted: October 31, 20221

Published: November 3, 2021

Copyright $\odot 2021$ by author(s) and Scientific Research Publishing Inc. This work is licensed under the Creative Commons Attribution International License (CC BY 4.0).

http://creativecommons.org/licenses/by/4.0/

(c) (i) Open Access

\begin{abstract}
A growing number of studies are now emphasizing the critical importance of learning and knowledge accumulation for firm-level competitiveness. Despite the growing awareness, relatively fewer project-based firms have institutionalized mechanisms to systematically capture new project knowledge and re-use it to improve the execution of subsequent projects. The peculiarity of projects presents unique challenges that make the cognitive approach to learning difficult to implement. As such, researchers are recommending the social constructivist perspective of learning as the most viable strategy for cultivating learning within and across projects. However, scant work has been undertaken from this sociological perspective to analyze how temporary organizations manage knowledge arising from and relating to projects. From this standpoint, the aim of this paper is to discuss the learning mechanisms of construction firms. The study adopted a quantitative strategy by employing a questionnaire survey into the learning practices of construction projects in Ghana. Drawing on preliminary findings from the literature, the study proposes a model for cultivating learning within projects from the social constructivist viewpoint. In the model, project management practitioners can purposefully nurture or structure a project learning activity through four mechanisms viz.: institutionalization, externalization, socialization and internalization. The proposed model is subsequently validated in an empirical study into the learning practices during the implementation of construction projects in Ghana. Based on the empirical results, it seems that knowledge sharing and transfers through the four aforementioned learning mechanisms proposed by the model are highly regarded within project management practice in Ghana.
\end{abstract}

\section{Keywords}

Social, Constructivist, Situated Learning, Mechanism, Projects, Codification, 
Cognitive Personalization

\section{Introduction}

In the modern economy, the foundations of organizational competitiveness have shifted from the resource-based view (RBV) to the knowledge-based view (KBV) of a firm [1] [2]. The literature on the knowledge-based theory of the firm suggests that it is the heterogeneity in knowledge possessed by different firms that determine their differential performance in the market place [3]. Accordingly, the competitiveness of the firm is contingent on its learning capabilities. This learning takes two generalized forms-cognitive and social constructivist perspectives. The cognitive learning perspective focuses on developing and implementing databases, tools and techniques to capture and codify knowledge. The social constructivist perspective, on the other hand, focuses on learning within a dynamic social process [4] [5]. From this standpoint, knowledge is not seen as a "resource" that is easily capturable; nor embedded in organizational processes. Rather, knowledge is seen to emerge as people interact recurrently in the context of established routines and procedures [6].

Likewise, the project-based organization (PBO) has emerged as a viable organizational structure to deal with the new features of the transitory and one-off demands, of a multiplex market. PBOs are organizational structures that entail the development of temporary systems for the completion of project tasks or activities [7] [8] [9]. Characterized by knowledge generation, knowledge application and potentially knowledge loss, project environments are seen as arenas suitable for executing learning. Consequently, learning within and across projects is now widely accepted as an important determinant of the firm-level competitiveness [10] [11].

Despite this growing awareness, relatively fewer project-based firms have institutionalized mechanisms to systematically capture new project-knowledge and re-use it to improve the execution of subsequent projects [12] [13]. The peculiarity of projects presents unique challenges when it comes to managing knowledge [13] [14] [15]. From the standpoint of project management (PM), a deeper knowledge of the processes for learning in project context will be beneficial to the development of projects and their outcomes [9]. In order to gain a better grasp of project learning, the fundamental question that arises is, "What is the optimum technique for integrating learning within and between projects" [16] [17]? As stated earlier, two conflicting viewpoints emerge in the literature: the cognitive learning approach and the social (situated) learning approach. The current literature on learning is dominated by the cognitive view [14] [18] [19] [20], where learning is regarded as a discrete undertaking, and as a matter of dissemination and absorption. However, with the recognition that knowledge is often tacit, situational, and ingrained within certain social groups and settings, researchers are beginning to recognize and emphasize the relevance of social 
constructivist perspective of learning [6] [21] [22]. This viewpoint conjectures most learning occurs socially in job practice through networking [23]. The practice then is utilized as the means of learning, with an emphasis on encouraging participants to engage in discourse, conversations, and storytelling as crucial methods for cultivating learning within a project [9]. The existence of limited studies on how temporary organization construct knowledge and learning from this perspective [24] calls for in-depth investigation into the social mechanisms for constructing and transforming knowledge. Thus, from a social constructivist perspective, the aim of this paper is to discuss the learning mechanisms of project-based firms. The study investigates whether, and how project-based firms in the construction industry are able to capitalize on knowledge that is generated during the execution of one project and their ability to utilize and transfer it to other projects.

\section{Research Background and Literature Review}

\subsection{Knowledge Conversion Processes}

Knowledge transformation is a brand-new field of study that is relevant to knowledge management. Knowledge transformation is a spiraling process that leads to new knowledge as a result of explicit and tacit knowledge interacting. It explicitly examines the transfer of information from one group to another [25]. Nonaka and Takeuchi [26] [27] proposed a valuable theory that explains how organizations may create, preserve, and apply knowledge despite its ethereal, even ephemeral characteristics. The theory of Nonaka and Takeuchi's [26] is based on four processes and four kinds of activities viz.: socialization, combination internalization and externalization. Socialization occurs when people's interactions aid in the transformation of one's tacit knowledge into another's [28]. When tacit knowledge is extracted from one's experience and translated into explicit knowledge, this is referred to as externalization [28]. Combination is the process of transforming explicit data into better explicit knowledge [28]. Finally, internalization is the process of integrating explicit knowledge into one's own wisdom [28]. Nonaka and Takeuchi's [26] outline four mechanisms for converting tacit knowledge to explicit knowledge and vice versa. The formal process by which tacit and explicit knowledge collide and combine is known as dialog. It necessitates people recognizing and sharing what they have learned informally through their experiences (socialization). This could happen, for example, when a project team's less experienced members receive expertise and advice from a more experienced team leader [28]. It's also important to connect explicit knowledge [28]. Recognizing that what arises from our experiences is worthy of formalization (externalization) and searching what already exists formally and making connections takes some work (combination). Learning by doing is significant since it suggests that a portion of the learning can only take place when people are confronted with the demands of their jobs [28]. Indeed, the complete cycle could serve as a model for on-the-job project management expertise de- 
velopment, combining knowledge creation and personal growth [28].

\subsection{Project Leaning}

Focusing our attention to the specific subject under investigation, an increasing number of studies [29] [30] [31] are underlining the vital relevance of knowledge accumulation in developing project competences. These scholars emphasize the critical significance that "project knowledge" gathered throughout a number of projects can play in achieving optimal results. Project learning is a broad notion that encompasses a variety of activities at several levels of the project's structure [28] [32] [33]. It can happen to a single employee, a project team, many project teams, a single corporation, and/or a group of businesses working on a single project. [28] [32]. The transformation step begins after relevant knowledge sources in problem solutions have been identified [34]. It occurs both within and between projects. To develop and transform knowledge in the project settings, two distinct strategies are used: codification and personalization strategies. Chiocchio et al. [28] argue that project-based learning is an important function of the knowledge transformation processes in project context. To generate and transform new knowledge, a variety of processes might be applied. One strategy for cross transferal of knowledge is to conduct systematic post-project reviews (PPRs) [35].

The development and exchange of intellectual capital in project scenarios is referred to as project learning [28]. Intra-project learning concentrates on activities that are exclusive to a single project and aids in the effective completion of the project by detecting and resolving issues as they arise [28]. When members of a project team brainstorm about how to complete a task or overcome obstacles, learning occurs [36]. The combination and cross-project exchange of lessons learnt in order to put fresh information into practice and develop new ideas is known as inter-project learning [32]. Information technology tools and employee groups geared at knowledge sharing inside the company are examples of tools that facilitate inter-project learning [37]. Prencipe and Tell [32] propose four categories of interproject learning mechanisms. These include: accumulation of experience, articulation of inborne Knowledge, the codification and reuse of new knowledge.

\section{Learning Mechanisms}

\section{1) Experience accumulation}

According to Levitt and March [38], the purpose of organizational learning is to achieve specific outcomes. Organizational learning is founded on historical experience enshrined in daily routines, tacit and pre-programmed processes, reflection of past experiences and the results of try and error [38]. Senge [39] defined experience accumulation as based on people's accumulated expertise as they move from project to project. Accumulating experience could be done by sharing experiences from past projects despite the fact that it is "an ad hoc approach of improving a strong project management competence" ([32], p. 584). 
The articulation and codification of knowledge, on the other hand, which demand more cognitive effort and resources, are more important in the development of interproject learning capabilities [40]. Researchers have suggested individuals can be placed through job rotation, specialization, and re-use of specialists as part of the experience accumulation process [32].

\section{2) Knowledge articulation}

The reflective practitioner's ability to explain practical knowledge is critical to learning [41]. Learning by thinking and learning by reflecting are two ways of articulating knowledge [41]. This can be described as learning-through-discussion and learning-through-confrontation [42], when you consider learning-by-doing and learning-by-using in accumulating experience. Varieties of processes such as reviews, meetings, and brainstorming could be utilized to articulate knowledge. Similarly, project meetings and reviews at the team level are described by Newell and Edelman [33] as building a common knowledge of what determines whether a project succeeds or fails.

\section{3) Knowledge codification}

In transitory organizations, the capacity to organize and systematize information can assist in information transfer as well as increase business efficiency and learning within the enterprise [32]. The ability to organize and codify information enables the invention of externalized knowledge that can be represented verbally or symbolically [32]. Prencipe and Tell [32] characterize learning-through-writing and re-writing as two techniques for knowledge codification. According to Newell and Edelman [33], knowledge codification is performed by keeping track of project outcomes in order to transmit learning to future initiatives.

\section{4) Learning support}

The measures project managers put in place to help the learning process are known as learning support. According to Swan et al. [43], when a project manager focuses on the technical as well as the social aspects of learning, both the utilization of current knowledge and the exploration of new information are maximized.

\subsection{Conceptual Framework}

By integrating the findings from the literature, the current study proposes the "IESI" conceptual model for cultivating learning in project from a social constructivist perspective (see Figure 1). Appreciating the learning process as a social effort led us to adopt the model suggested by Nonaka and Takeuchi [26] based on the processes of socialization, internalization, combination and externalization. However, combination is exempted from this study because of the theoretical views of the current study-social constructivist perspective of learning. For the remaining social processes to be effective, there must be institutions or learning supports [20]. By relating these three processes and learning 


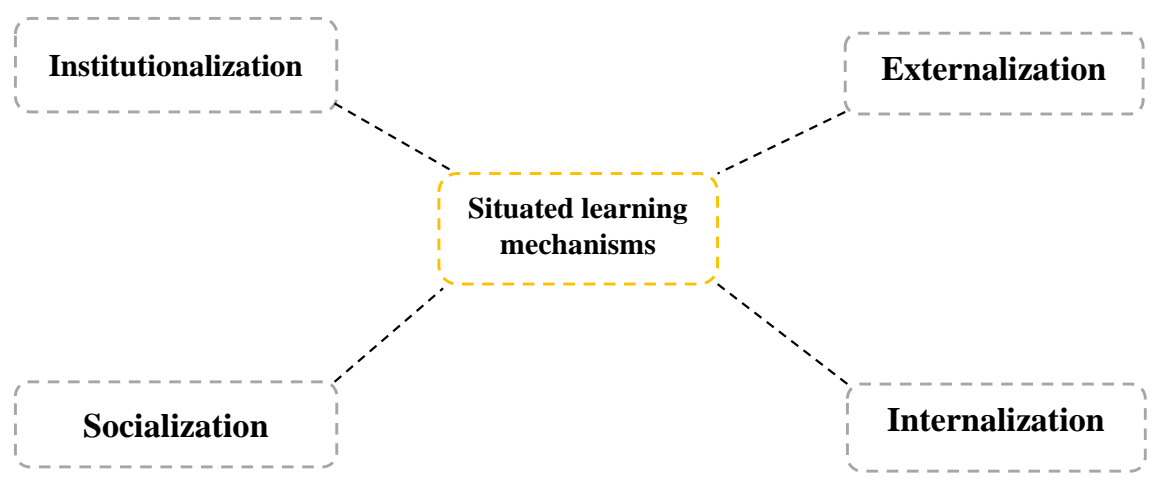

Figure 1. The IESI conceptual model for cultivating learning from a social perspective. Source Authors' construct (2021).

support to the individual, project and organisational levels, we developed four (4) constructs that enabled us to categorize a variety of social mechanisms that temporary organizations engage to construct knowledge and learning viz.: institutionalization, socialization, externalization, and internalization.

The proposed framework is a cycle of four processes. The first process (institutionalization) involves the recognition of projects as vehicles of organizational learning [44] and building the necessary institutions to cultivate learning [20]. Time for reflective practices must be explicitly built into project schedules and learning outcomes must be evaluated. The second process involves the externalization of knowledge. Being able to articulate practical knowledge is an important facet of the reflective practitioner [41]. Knowledge externalization is described as learning by thinking and learning by reflecting [41]. It is also referred to as learning-by-discussing and learning-by-confronting [42], when compared to learning-by-using and learning-by-doing in experience accumulation processes. Several mechanisms could be used for knowledge externalization such as reviews, meetings, and brainstorming. The third process involves facilitating socialization. Socialization occurs when people's interactions help in the transformation of one's tacit knowledge into another's [28]. This involves fostering interaction platforms for team members to exchange ideas. The emphasis in this mechanism of knowledge conversion is on learning and knowledge management being intimately conjoined to individuals and their activities within a practice context [6]. Therein, there are opportunities to intentionally influence or structure socio-cultural conditions and people's actions to improve knowledge creation and learning in a specific situation [6]. The fourth process involves experience internalization (accumulation). Even though it is "a haphazard technique to increase a dynamic project working capability," internalization or experience accumulation could be achieved by individual sharing of past project experiences ([32], p. 584). Mechanisms that induce internalization include job rotation, specialization, on-the-job training and re-use of expert. The succeeding section empirically validates this model within construction project organizations in Ghana. 


\section{Research Methodology}

Given the philosophical perspectives described in literature, it can be stated that, positivist philosophy utilizes observable approach in analyzing causal links which leads to hypothesis and theory testing [45] [46]. It looks for inferences from the study's larger population [47]. Conversely, the interpretivism paradigm, involves theory building and in-depth investigations of a phenomenon [45]. Drawing on these assumptions in relation to the objectives of this study, the philosophical perspective of this study is articulated as follows-at the ontological level, this study takes a realism stance. This is because the mechanisms for cultivating the social constructivist perspective of learning are pre-existing in the literature. However, these variables have not been optimized in explaining learning within the context of projects [16]. From an epistemological standpoint, this study believed that the complex interactions of a learning activity inside and between projects can be investigated using a methodical but simple steady approach. The research might also be conducted without prejudice, allowing for objective conclusions to be drawn from data acquired from a distance [46]. As a result, positivist tradition was the epistemological perspective in this study. This was couched within an inductive approach.

\subsection{Questionnaire Survey}

A lesson learned oriented survey was completed by 203 construction professionals who have hands-on experience in managing projects in Ghana. The survey contained two question sets. The first set asked the respondents their background in project management. The second set focused on how the organizations produce lessons learned within and across project implementation, using a five-point Likert scale ( 1 = none exists, 2 = inadequate implementation, $3=$ neither good or bad, $4=$ good, 5 = strong implementation). Sampling of the respondents was non-probabilistic and the respondents to the questionnaire represent different roles and categories within their respective firms. In order to put the report in context and give the reader and end users a better knowledge of the respondents' characteristics, this section presents an empirical analysis of the characteristics of the key sources of primary data. The background information of the respondents included their sex, the professional capacity under which they manage or managed projects, professional qualification, hands-on experience in managing projects, the average number of projects supervised or co-supervised, managerial level of managing projects, and the average financial size of projects managed. See Table 1 for full details.

\subsection{Data Analysis Techniques}

The data collected from the questionnaire were analyzed with the assistance of Statistical Package for Social Science. Mean score ranking was deployed to prioritize the measurement items. Factor analysis was performed on the data sets. There are five general steps to factor analysis: 1) assessing applicability; 2) 
Table 1. Background characteristics.

\begin{tabular}{llrr}
\hline & Variables/Categories & N & Percent \\
\hline Sex & & & \\
& Male & 159 & 78.3 \\
& Female & 44 & 21.7 \\
& Prefer not to say & 2 & 0.99 \\
Total & 203 & 100.0 \\
\hline
\end{tabular}

Which professional capacity did you or do you manage or managed projects

Project manager 52

Architect

25.6

Quantity surveyor

Engineer

$\begin{array}{ll}76 & 37.4\end{array}$

Others

$43 \quad 21.2$

$9 \quad 4.4$

Total

$203 \quad 100.0$

What is your professional qualification

$\begin{array}{lll}\text { Project management professional } & 34 & 16.7\end{array}$

$\begin{array}{lll}\text { Ghana institution of architects } & 24 & 11.8\end{array}$

$\begin{array}{lll}\text { Ghana institution of surveyors } & 60 & 29.6\end{array}$

$\begin{array}{lll}\text { Ghana institution of engineers } & 34 & 16.7\end{array}$

$\begin{array}{lll}\text { Not applicable } & 51 & 25.1\end{array}$

Total

$203 \quad 100.0$

Hands-on experience in managing projects

$\begin{array}{lcc}1-5 \text { years } & 38 & 18.7 \\ 6-10 \text { years } & 77 & 37.9 \\ 11-15 \text { years } & 43 & 21.2 \\ 16-20 \text { years } & 37 & 18.2 \\ \text { Over } 20 \text { years } & 8 & 3.9 \\ \text { Total } & 203 & 100.0\end{array}$

Average number of projects supervised or co-supervised

$\begin{array}{lcc}1-5 \text { projects } & 50 & 24.6 \\ 6 \text { - } 10 \text { projects } & 39 & 19.2 \\ 11-15 \text { projects } & 33 & 16.3 \\ 16-20 \text { projects } & 25 & 12.3 \\ \text { Over } 20 \text { projects } & 56 & 27.6 \\ \text { Total } & 203 & 100.0\end{array}$




\section{Continued}

\begin{tabular}{lcc}
\hline At what managerial level do you or did you manage/d the project(s) & - & \\
Top level of management & 58 & 28.6 \\
Middle level of management & 57 & 28.1 \\
Supervisory or at the Team level & 88 & 43.3 \\
Total & 203 & 100.0 \\
\hline Average financial size of project/s managed & - & \\
$\leq 5$ million dollars & 108 & 53.2 \\
$\$ 5,000,001-\$ 50,000,000$ & 54 & 26.6 \\
$\$ 50,000,001-\$ 100,000,000$ & 30 & 14.8 \\
Over $\$ 100,000,000$ & 11 & 5.4 \\
Total & 203 & 100.0 \\
\hline
\end{tabular}

Source: Authors' fieldwork (2021).

determining the number of factors through factor extraction; 3) grouping the variables into factors according to factor loading; 4) producing weighted factor scores; and 5) assessing factor reliability. First, we assessed applicability of the factor analysis process. Since the goal of factor analysis is to obtain factors, the variables must be related to each other for the factor model to be appropriate [48]. Second, we determined the number of factors. In this survey, estimates were obtained for the initial factors through principal component analysis. Third, we grouped the variables into factors according to factor loading. Fourth, weighted factor scores were determined by taking the average of the score for each item in a factor. Fifth, each factor's reliability was computed using Cronbach's alpha. Table 6 provides the factor analysis and reliability results for the project management learning practices.

\section{Results}

\subsection{Pretesting of Dataset}

The internal consistency of the grading scale and survey questionnaire was assessed using the Cronbach's Alpha statistic. The reliability analysis produced a Cronbach's Alpha of 0.914, which is higher than the acceptable minimum value of 0.7 [49]. The Shapiro-Wilk test was used to determine the dataset's normality [50], and the findings, as given in Table 2, showed that the dataset of the social constructivist learning mechanisms was not normally distributed at the 95 percent confidence interval. The Kruskal-Wallis test, a rank-based nonparametric test, was employed to see if there were statistically significant differences in expert responses depending on their professional backgrounds. The Kruskal-Wallis test results in Table 2 revealed that none of the situated learning activities were statistically distinct, implying that expert replies were unanimous and could be analyzed as a single unit. 
Table 2. Mean score and RII ranking, normality and Kruskal Wallis test of situated learning activities.

\begin{tabular}{|c|c|c|c|c|c|}
\hline Social Learning Activities/Mechanisms & Mean & Std. Dev. & Rank & $\begin{array}{l}\text { Shapiro-Wilk } \\
\text { (p-value) }\end{array}$ & $\begin{array}{l}\text { Kruskal } \\
\text { Wallis Test } \\
\text { (p-value) }\end{array}$ \\
\hline $\begin{array}{l}\text { Create routines to internalize tacit knowledge stemming from } \\
\text { individual and team reflectivity }\end{array}$ & 4.21 & 0.882 & 1 & 0.000 & 0.986 \\
\hline Encourage job rotation & 4.07 & 0.988 & 2 & 0.000 & 0.450 \\
\hline Encourage specialization & 4.06 & 0.968 & 3 & 0.000 & 0.806 \\
\hline $\begin{array}{l}\text { Foster meetings with team members from previous and next phases of } \\
\text { the projects }\end{array}$ & 4.04 & 0.971 & 4 & 0.000 & 0.546 \\
\hline $\begin{array}{l}\text { Embed a mentor in each project team to provide support for team } \\
\text { members }\end{array}$ & 4.03 & 0.946 & 5 & 0.000 & 0.190 \\
\hline Have past project audits discussed and used in current project/s & 3.94 & 1.113 & 6 & 0.000 & 0.099 \\
\hline $\begin{array}{l}\text { Foster communities of practice where project managers and team } \\
\text { members can meet and discuss }\end{array}$ & 3.92 & 1.193 & 7 & 0.000 & 0.465 \\
\hline Nurture a project culture open to experimentation and new insights & 3.73 & 1.113 & 8 & 0.000 & 0.002 \\
\hline Articulate cause and effect linkages of past success/failure & 3.71 & 1.292 & 9 & 0.000 & 0.417 \\
\hline $\begin{array}{l}\text { Create room for on-the-job training of team members as part of } \\
\text { competency development. }\end{array}$ & 3.71 & 1.420 & 10 & 0.000 & 0.043 \\
\hline $\begin{array}{l}\text { Articulate practical knowledge pertinent from past phase to new phase } \\
\text { of the project (externalization) }\end{array}$ & 3.67 & 1.192 & 11 & 0.000 & 0.870 \\
\hline $\begin{array}{l}\text { During project execution, you discuss the set of problems encountered } \\
\text { during the project }\end{array}$ & 3.59 & 1.192 & 12 & 0.000 & 0.791 \\
\hline $\begin{array}{l}\text { Institutionalize mechanisms for team members to freely reveal their } \\
\text { expertise and views concerning solutions to problems rather than } \\
\text { firmly instructing them to follow predefined procedures }\end{array}$ & 3.56 & 1.350 & 13 & 0.000 & 0.236 \\
\hline $\begin{array}{l}\text { Ensure psychological safety among team members to facilitate working } \\
\text { relationships and candid sharing }\end{array}$ & 3.53 & 1.401 & 14 & 0.000 & 0.162 \\
\hline $\begin{array}{l}\text { Create chat rooms for socialization and exchange of ideas among team } \\
\text { members }\end{array}$ & 3.34 & 1.316 & 15 & 0.000 & 0.031 \\
\hline $\begin{array}{l}\text { We see the implementation of projects as learning opportunities and } \\
\text { institutionalize mechanisms to manage knowledge relating to, and } \\
\text { arising from projects }\end{array}$ & 3.22 & 1.429 & 16 & 0.000 & 0.010 \\
\hline Orientate team members towards learning & 3.19 & 1.445 & 17 & 0.000 & 0.016 \\
\hline $\begin{array}{l}\text { We explicitly build time in project schedules for critical reflections on } \\
\text { project outcome (not just at the end of project), and also conduct } \\
\text { end-of-phase reviews as the project progresses }\end{array}$ & 3.07 & 1.384 & 18 & 0.000 & 0.066 \\
\hline Evaluate learning outcomes of team members & 3.05 & 1.480 & 19 & 0.000 & 0.016 \\
\hline $\begin{array}{l}\text { Create reward systems that encourage knowledge sharing among team } \\
\text { members }\end{array}$ & 2.86 & 1.558 & 20 & 0.000 & 0.011 \\
\hline
\end{tabular}




\subsection{Mean Score Ranking of the Social Mechanisms of Learning}

The mean and standard deviations of the social mechanisms for learning are shown in this section. Table 2 presents means and standard deviations of the main situated learning variables. Conforming to the conventional critical mean value, if a variable has a mean value of 2.50 or higher, it is considered critically essential [10]. The findings demonstrated that all of the variables had mean values ranging from 2.5 to 5.0, indicating their relative importance and significance in explaining social learning during project implementation. The standard deviations in Table 2 indicate how far the experts' overall ratings of a factor deviate from the associated mean score. When two or more factors have the same mean score, the one with the lowest standard deviation was assigned a higher ranking [47]. The standard deviations were used to measure consensus in the experts' ratings. Although there are no small or large standard deviations, lesser values are preferred over larger scores. For this reason, although some factors had standard deviations greater than 1 , they were nevertheless evaluated for further analysis due to the closer proximity of their mean scores to 3.50 .

\subsection{Factor Analysis of the Social Constructivist Learning Activities}

Twenty (20) social constructivist learning mechanisms were identified from the literature and it was essential to cluster them for easy interpretation. As a result, factor analysis was used to group the factors in the study. In factor analysis, determining the eigenvalues is the first step. At the first iteration, eigenvalues greater than 0.50 suggest that the variable is significant. This means that factors with eigenvalues less than 0.50 are less significant and must be dropped. The communality results of the factor analysis performed with initial values of 1.00 are shown in Table 3.

Table 3. Communalities of situated learning activities.

\begin{tabular}{|c|c|c|}
\hline & Initial & Extraction \\
\hline $\begin{array}{l}\text { We see the implementation of projects as learning opportunities and institutionalize mechanisms to } \\
\text { manage knowledge relating to, and arising from projects }\end{array}$ & 1 & 0.730 \\
\hline $\begin{array}{l}\text { We explicitly build time in project schedules for critical reflections on project outcome (not just at the } \\
\text { end of project), and also conduct end-of-phase reviews as the project progresses }\end{array}$ & 1 & 0.698 \\
\hline Orientate team members towards learning & 1 & 0.809 \\
\hline Create reward systems that encourage knowledge sharing among team members & 1 & 0.788 \\
\hline Evaluate learning outcomes of team members & 1 & 0.809 \\
\hline Nurture a project culture open to experimentation and new insights & 1 & 0.720 \\
\hline $\begin{array}{l}\text { Institutionalize mechanisms for team members to freely reveal their expertise and views concerning } \\
\text { solutions to problems rather than firmly instructing them to follow predefined procedures }\end{array}$ & 1 & 0.698 \\
\hline Articulate practical knowledge pertinent from past phase to new phase of the project (externalization). & 1 & 0.692 \\
\hline Articulate cause and effect linkages of past success/failure & 1 & 0.712 \\
\hline
\end{tabular}




\section{Continued}

Have past project audits discussed and used in current project/s

During project execution, you discuss the set of problems encountered during the project

Foster meetings with team members from previous and next phases of the projects

Embed a mentor in each project team to provide support for team members

Create routines to internalize tacit knowledge stemming from individual and team reflectivity

On-the-job training of team members as part of competency development

Create chat rooms for socialization and exchange of ideas among team members

Foster communities of practice where project managers and team members can meet and discuss.

Ensure psychological safety among team members to facilitate working relationships and candid sharing

Encourage Job rotation

Extraction Method: Principal Component Analysis. Source: Authors' field survey (2021).

In contrast to the descriptive analysis' prior findings, which indicated that all variables are critical because their means are more than 2.50, Table 3 shows that, the eigenvalues of one of the factors (encouraging specialization (0.494) was less than 0.50 . As a result, this variable was not included in the rotation analysis because it was not significant. The remaining nineteen variables were subjected to iterations using component matrix factor analysis. However, two other variables (communities of practice and chat rooms for socialization) had cross loadings challenges and were exempted. The initial eigen values, extracted sum of squared loadings and the rotation sum of squared loadings of the remaining seventeen variables are presented in Table 4.

In order to group inter-dependent variables into descriptive categories and classify the variables into types with similar characteristics or behaviour, principal component matrix was employed. It can be inferred from Table 5 that the component matrix re-grouped the remaining 17 factors under four components namely-institutionalization, externalization, socialization and internalization. The results of the extracted sums of squared loading show principal component 1(Institutionalization) explains $40.937 \%$ of variance. Principal component 2 (externalization) explains $19.324 \%$ of variance. Principal component 3 (socialization) explains $7.603 \%$ and principal component 4 (internalization) explains $4.876 \%$ of variance.

\subsubsection{Component 1: Institutionalization}

The first principal component (PC1) is responsible for 40.937 of the total variances and contains six (6) specific factors. The factors and their respective factor loading (eigenvalue) are presented in Table 5 and they include-seeing projects as learning objects (85.1\%), building time in project schedules for critical reflections (80.2\%), orientating team members towards learning (89.5\%), creating rewards that encourage knowledge sharing (83.6\%), evaluating learning 
Table 4. Total variance explained of social learning activities.

\begin{tabular}{|c|c|c|c|c|c|c|c|c|c|}
\hline \multirow[b]{2}{*}{ Component } & \multicolumn{3}{|c|}{ Initial Eigenvalues } & \multicolumn{3}{|c|}{ Extraction Sums of Squared Loadings } & \multicolumn{3}{|c|}{ Rotation Sums of Squared Loadings } \\
\hline & Total & $\begin{array}{c}\% \text { of } \\
\text { Variance }\end{array}$ & Cumulative \% & Total & $\begin{array}{c}\% \text { of } \\
\text { Variance }\end{array}$ & Cumulative \% & Total & $\begin{array}{c}\% \text { of } \\
\text { Variance }\end{array}$ & Cumulative \% \\
\hline 1 & 6.141 & 40.937 & 40.937 & 6.141 & 40.937 & 40.937 & 4.163 & 27.755 & 27.755 \\
\hline 2 & 2.899 & 19.324 & 60.262 & 2.899 & 19.324 & 60.262 & 3.159 & 21.062 & 48.817 \\
\hline 3 & 1.141 & 7.603 & 67.865 & 1.141 & 7.603 & 67.865 & 1.904 & 12.696 & 61.513 \\
\hline 4 & 0.731 & 4.876 & 72.741 & 0.731 & 4.876 & 72.741 & 1.684 & 11.228 & 72.741 \\
\hline 5 & 0.688 & 4.124 & 74.672 & & & & & & \\
\hline 6 & 0.578 & 3.852 & 76.593 & & & & & & \\
\hline 7 & 0.501 & 3.337 & 79.931 & & & & & & \\
\hline 8 & 0.480 & 3.201 & 83.132 & & & & & & \\
\hline 9 & 0.452 & 3.015 & 86.147 & & & & & & \\
\hline 10 & 0.411 & 2.739 & 88.886 & & & & & & \\
\hline 11 & 0.402 & 2.682 & 91.568 & & & & & & \\
\hline 12 & 0.340 & 2.265 & 93.832 & & & & & & \\
\hline 13 & 0.324 & 2.158 & 94.672 & & & & & & \\
\hline 14 & 0.294 & 1.959 & 95.791 & & & & & & \\
\hline 15 & 0.266 & 1.773 & 97.565 & & & & & & \\
\hline 16 & 0.220 & 1.465 & 99.029 & & & & & & \\
\hline 17 & 0.146 & 0.971 & 100.000 & & & & & & \\
\hline
\end{tabular}

Extraction Method: Principal Component Analysis. Source: Authors' field survey (2021).

Table 5. Rotated component matrix ${ }^{\mathrm{a}}$ of Social Learning mechanisms within and across projects.

\begin{tabular}{|c|c|c|c|c|}
\hline & \multicolumn{4}{|c|}{ Component } \\
\hline & 1 & 2 & 3 & 4 \\
\hline $\begin{array}{l}\text { We see the implementation of projects as learning opportunities and institutionalize } \\
\text { mechanisms to manage knowledge relating to, and arising from projects }\end{array}$ & 0.851 & & & \\
\hline $\begin{array}{l}\text { We explicitly build time in project schedules for critical reflections on project outcome } \\
\text { (not just at the end of project), and also conduct end-of-phase reviews as the project } \\
\text { progresses }\end{array}$ & 0.802 & & & \\
\hline Orientate team members towards learning & 0.895 & & & \\
\hline Create reward systems that encourage knowledge sharing among team members & 0.836 & & & \\
\hline Evaluate learning outcomes of team members & 0.868 & & & \\
\hline Nurture a project culture open to experimentation and new insights & 0.587 & & & \\
\hline $\begin{array}{l}\text { Institutionalize mechanisms for team members to freely reveal their expertise and } \\
\text { views concerning solutions to problems rather than firmly instructing them to follow } \\
\text { predefined procedures }\end{array}$ & & 0.690 & & \\
\hline
\end{tabular}




\section{Continued}

Articulate practical knowledge pertinent from past phase to new phase of the project (externalization).

0.786

0.693

0.789

0.712

During project execution, you discuss the set of problems encountered during the project

Ensuring psychological safety

0.803

Embed a mentor in each project team to provide support for team members

Create routines to internalize tacit knowledge stemming from individual and team

reflectivity

On-the-job training

Job rotation

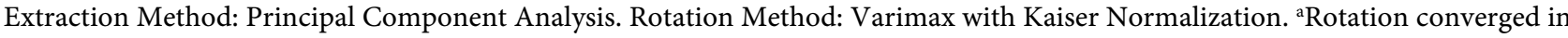
6 iterations. Source: Authors' field survey (2021).

outcomes of team members $(86.8 \%)$, and nurturing a project culture open to experimentation and new insights (58.7\%).

\subsubsection{Component 2: Externalization}

Principal component two accounted for 19.324 of the total variances and contains five (5) specific factors. The factors and the eigenvalues of the second component are outlined as follows-mechanisms for team members to freely reveal their expertise (69.0), articulate practical knowledge pertinent from past phase to new phase (78.6\%), articulate cause and effect linkages of past success/failure (69.3\%), have past project audits discussed and used in current project/s (78.9\%), during project execution you discuss the set of problems encountered during the project (71.2\%).

\subsubsection{Component 3: Socialization}

Principal component three accounted for 7.603 of the total variances and contains three (3) specific factors. The respective factor loadings of this component are listed as-ensuring psychological safety of team members (74.6\%), fostering meetings with team members from previous and next phases of the projects (76.8\%) and embedding a mentor in each project team to provide support for team members $(80.3 \%)$.

\subsubsection{Component 4: Internalization}

The fourth component accounted for 4.876 of the total variances and contains three (3) factors namely: creating routines to internalize tacit knowledge (72.6\%), on-the-job training (63.32\%) and encouraging job rotation (62.4\%). Table 6 summarizes the final results of the factor analysis. 
Table 6. Factor analysis of social constructivist learning mechanisms.

Item mean Factor Loadings $\begin{gathered}\text { Factor } \\ \text { reliability }\end{gathered}$ Factor mean

\section{Institutionalization}

We see the implementation of projects as learning opportunities and institutionalize mechanisms to manage knowledge relating to,

We explicitly build time in project schedules for critical reflections on project outcome (not just at the end of project), and also conduct end-of-phase reviews as the project progresses

Orientate team members towards learning

Create reward systems that encourage knowledge sharing among team members

$2.86 \quad 0.836$

Evaluate learning outcomes of team members

Nurture a project culture open to experimentation and new insights

3.73

0.587

Overall Mean (Institutionalization)

\section{Externalization}

Institutionalize mechanisms for team members to freely reveal their expertise and views concerning solutions to problems rather than firmly instructing them to follow predefined procedures

Articulate practical knowledge pertinent from past phase to new phase of the project (externalization).

$3.665 \quad 0.786$

Articulate cause and effect linkages of past success/failure

$3.714 \quad 0.693$

Have past project audits discussed and used in current project/s

During project execution, you discuss the set of problems encountered during the project

Overall (Externalization)

\section{Socialization}

Ensuring psychological safety of team members

Foster meetings with team members from previous and next phases of the projects

$4.044 \quad 0.768$

Embed a mentor in each project team to provide support for team members

$4.034 \quad 0.803$

Overall Mean (Socialization)

\section{Internationalization}

Create routines to internalize tacit knowledge stemming from individual and team reflectivity

$4.207 \quad 0.726$

On-the-job training

Job rotation

4.071

0.645

Overall Mean (Internationalization)

Extraction Method: Principal Component Analysis. Rotation Method: Varimax with Kaiser Normalization. ${ }^{\text {a }}$ Rotation converged in 6 iterations. Source: Researcher's field survey (2021). 


\section{Discussion of Empirical Results}

In appreciating the learning process as a social effort, the current study adopted the model suggested by Nonaka and Takeuchi [26] based on the processes of socialization, internalization, combination and externalization to understand whether and how temporary organizations cultivate learning from a social constructivist perspective. However, knowledge combination is exempted from this study because of the theoretical view of the study. For the three remaining knowledge conversion and learning processes to be functional, there must be institutions or learning supports [20]. By relating these three processes and learning support, the current study arrived at four (4) components that enabled us to categorize a variety of social mechanisms that temporary organizations use to construct situated (social) learning viz: institutionalization, socialization, externalization, and internalization

\subsection{Grouping 1: Institutionalization}

This factor grouping recorded an overall mean of 3.187. This underlying group highlights the role of institutions for the cultivation of situated (social) learning within and across projects implementations and it is represented by six (6) measurement items. They include-seeing projects as learning objects, building time in project schedules for critical reflections, orientating team members towards learning, creating rewards that encourage knowledge sharing, evaluating learning outcomes of team members, and nurturing a project culture open to experimentation and new insights. The result is interpreted as follows-for the cultivation of situated (social) learning, projects must be seen as vehicles of organizational learning [44] and the necessary institutions put in place [20]. The measures put in place to help the learning process are referred to as institutions. These institutions have both technical and social dimensions. In answering the second part of the research question on "whether or not temporary organizations practice situated (social) learning", the findings from the empirical study into the learning practices of construction projects in Ghana reveal that, most of the organizations nurtured the necessary institutions for situated (social) learning. The most practiced item under this factor grouping is the nurturing of a project culture open to experimentation and new insights (3.73). On the contrary, the creation of reward systems to encourage knowledge sharing among team members had a low mean value of $\mathbf{2 . 8 6}$ indicative of the fact that it might not be practiced or its implementation is inadequate.

\subsection{Grouping 2: Externalization}

Being able to articulate practical knowledge is an important facet of the reflective practitioner [41]. Knowledge externalization is described as learning-by-discussing and learning-by-confronting [41]. "Externalization" is an essential element of the situated (social) process. The overall mean score for this factor grouping is 3.693. This factor grouping contains five (5) specific factors. They are outlined 
as follows-mechanisms for team members to freely reveal their expertise, articulate practical knowledge pertinent from past phase to new phase, articulate cause and effect linkages of past success/failure, have past project audits discussed and used in current project/s, during project execution we discuss the set of problems encountered during the project. Knowledge sharing and transfer through "externalization" is highly regarded during project implementation according to the empirical findings. The most practiced items under this factor grouping are-having past project audits discussed and used in current project/s and the articulation of cause and effect linkages of past success/failure with mean values of 3.936 and 3.714 respectively.

\subsection{Grouping 3: Socialization}

Socialization occurs when people's interactions help in the transformation of one's tacit knowledge into another's [28]. This involves fostering interaction platforms for team members to exchange ideas. The emphasis in this mechanism of knowledge conversion is on learning and knowledge management being intimately conjoined to individuals and their activities within a practice context. According to previous studies, the acquisition and transfer of knowledge in project settings are largely reliant on social practices, processes and patterns, in ways that emphasize the significance and necessity of the social constructivist perspective of learning [21] [51]. It is therefore not surprising that the empirical results reveal project organizations regard social processes as an important enabler in the cultivation of situated learning-with an overall mean score of 3.773. The sub-attributes of this construct include three (3) specific factors-ensuring psychological safety of team members, fostering meetings with team members from previous and next phases of the projects and embedding a mentor in each project team to provide support for team members. According to the empirical findings, all the attributes are highly regarded during the implementation of construction projects in Ghana.

\subsection{Grouping 4: Internalization}

Internalization or experience accumulation is when explicit knowledge is integrated into one's own wisdom [28]. This underlying factor had overall mean value of 4.012 . The processes of accumulating experience include project personnel being put on job rotation, specialization, on-the-job training and re-use of expertise [32]. In the ensuing discussion, the project managers confirmed that, routines to internalize tacit knowledge stemming from individual and team reflectivity (4.207), job rotation (4.071) and on-the-job training (4.059) are characteristic of their operations.

\section{Conclusion}

The objective of this study involves digesting current understanding of learning mechanisms from a social constructivist perspective, which could be adopted to 
generate learning within and across projects. Based on the review of extant literature, a questionnaire was designed to validate twenty (20) social learning mechanisms within project implementation in the Ghanaian construction industry. Drawing on the findings of the survey, this paper argues that project management practitioners can purposefully nurture or structure a learning environment within their projects through four social mechanisms viz.: institutionalization, socialization externalization, and internalization. These elements constitute a conceptual architecture or model to support and guide project situated learning activity. The study contributes significantly to both project management and organizational learning knowledge. Most engrossing, is its contribution to project knowledge management in presenting a unique and in-depth empirical study on project learning which is manifested through institutionalization, socialization externalization, and internalization. Theoretically, researchers can draw from the outcome of the study to understand how learning occurs in project environments. This objective also highlights the prime importance of purposefully and systematically attending to the social construction of learning (situated learning activity) as a normal part of project management practice. The survey results offer implications for project managers to use in focusing situated learning activities within and between projects. However, the findings should be interpreted against this limitation. Since learning itself cannot be designed and ultimately belongs to the realm of experience and practice, the proposed conceptual architecture for learning provides the critical elements for learners to design social infrastructures that foster their learning. Therefore, the model presented in this paper is not intended to represent a prescription for facilitating learning within projects. Rather, it forms a framework of concepts that project participants can use to aid their reflection on project learning practices.

\section{Conflicts of Interest}

The authors declare no conflicts of interest regarding the publication of this paper

\section{References}

[1] Nguyen, T.N.Q., Ngo, L.V., Northey, G. and Siaw, C.A. (2019) Realising the Value of Knowledge Resources and Capabilities: An Empirical Study. Journal of Knowledge Management, 23, 374-395. https://doi.org/10.1108/JKM-09-2016-0372

[2] Grant, R.M. (1996) Toward a Knowledge-Based Theory of the Firm. Strategic Management Journal, 17, 109-122. https://doi.org/10.1002/smj.4250171110

[3] Gassmann, O. and Keupp, M.M. (2007) The Competitive Advantage of Early and Rapidly Internationalising SMEs in the Biotechnology Industry: A Knowledge-Based View. Journal of World Business, 42, 350-366. https://doi.org/10.1016/j.jwb.2007.04.006

[4] Hansen, M.T., Nohria, N. and Tierney, T. (1999) What's Your Strategy for Managing Knowledge? Harvard Business Review, 77, 106-116.

[5] Desouza, K.C. (2003) Barriers to Effective Use of Knowledge Management Systems 
in Software Engineering. Communications of the ACM, 46, 99-101. https://doi.org/10.1145/602421.602458

[6] Sense, A.J. (2008) Conceptions of Learning and Managing the Flow of Knowledge in the Project-Based Environment. International Journal of Managing Projects in Business, 1, 33-48.

[7] Pemsel, S. and Müller, R. (2012) The Governance of Knowledge in Project-Based Organizations. International Journal of Project Management, 30, 865-876. https://doi.org/10.1016/j.ijproman.2012.02.002

[8] Pemsel, S., Söderlund, J. and Wiewiora, A. (2018) Contextualising Capability Development: Configurations of Knowledge Governance Mechanisms in Project-Based Organizations. Technology Analysis \& Strategic Management, 30, 1226-1245. https://doi.org/10.1080/09537325.2018.1459538

[9] Sense, A.J. (2007) Structuring the Project Environment for Learning. International Journal of Project Management, 25, 405-412. https://doi.org/10.1016/j.ijproman.2007.01.013

[10] Guribie, F.L., Tengan, C. and Kuebutornye, N. (2018) Knowledge Management Practice in the Ghanaian Construction Industry: A Case Study of 4 Firms in The Tamale Metropolis. Journal of Information \& Knowledge Management, 8, 83-88.

[11] Guribie, F.L. and Tengan, C. (2019) A Proposed Knowledge Management Implementation Framework for the Ghanaian Construction Industry. Journal of Building Construction and Planning Research, 7, 1-10. https://doi.org/10.4236/jbcpr.2019.71001

[12] Todorović, M.L., Petrović, D.T., Mihić, M.M., Obradović, V.L. and Bushuyev, S.D. (2015) Project Success Analysis Framework: A Knowledge-Based Approach in Project Management. International Journal of Project Management, 33, 772-783. https://doi.org/10.1016/j.ijproman.2014.10.009

[13] Duffield, M.S. and Whitty, S.J. (2015) Developing a Systemic Lessons Learned Knowledge Model for Organisational Learning through Projects. International Journal of Project Management, 33, 311-324. https://doi.org/10.1016/j.ijproman.2014.07.004

[14] Mainga, W. (2017) Examining Project Learning, Project Management Competencies and Project Efficiency in Project-Based Firms (PBFs). International Journal of Managing Projects in Business, 10, 454-504.

https://doi.org/10.1108/IJMPB-04-2016-0035

[15] Schindler, M. and Eppler, M.J. (2003) Harvesting Project Knowledge: A Review of Project Learning Methods and Success Factors. International Journal of Project Management, 21, 219-228. https://doi.org/10.1016/S0263-7863(02)00096-0

[16] Sense, A.J. (2007) Stimulating Situated Learning within Projects: Personalizing the Flow of Knowledge. Knowledge Management Research \& Practice, 5, 13-21. https://doi.org/10.1057/palgrave.kmrp.8500124

[17] McClory, S., Read, M. and Labib, A. (2017) Conceptualising the Lessons-Learned Process in Project Management: Towards a Triple-Loop Learning Framework. International Journal of Project Management, 35, 1322-1335.

https://doi.org/10.1016/j.ijproman.2017.05.006

[18] Ajmal, M., Helo, P. and Kekäle, T. (2010) Critical Factors for Knowledge Management in Project Business. Journal of Knowledge Management, 14, 156-168. https://doi.org/10.1108/13673271011015633

[19] Lindner, F. and Wald, A. (2011) Success Factors of Knowledge Management in Temporary Organizations. International Journal of Project Management, 29, 
877-888. https://doi.org/10.1016/j.ijproman.2010.09.003

[20] Kotnour, T. (2000) Organizational Learning Practices in the Project Management Environment Learning. International Journal of Quality \& Reliability Management, 17, 393-406.

[21] Bartsch, V., Ebers, M. and Maurer, I. (2013) Learning in Project-Based Organizations: The Role of Project Teams' Social Capital for Overcoming Barriers to Learning. International Journal of Project Management, 31, 239-251.

https://doi.org/10.1016/j.ijproman.2012.06.009

[22] Bresnen, M., Edelman, L., Newell, S., Scarbrough, H. and Swan, J. (2003) Social Practices and the Management of Knowledge in Project Environments. International Journal of Project Management, 21, 157-166. https://doi.org/10.1016/S0263-7863(02)00090-X

[23] Sense, A.J. (2007) Learning within Project Practice: Cognitive Styles Exposed. International Journal of Project Management, 25, 33-40.

https://doi.org/10.1016/j.ijproman.2006.06.004

[24] Sense, A.J. (2009) The Social Learning Character of Projects and Project Teams. International Journal of Knowledge Management Studies, 3, 195-208. https://doi.org/10.1504/IJKMS.2009.028836

[25] Szulanski, G. (2000) The Process of Knowledge Transfer: A Diachronic Analysis of Stickiness. Organizational Behavior and Human Decision Processes, 82, 9-27. https://doi.org/10.1006/obhd.2000.2884

[26] Nonaka, I. and Takeuchi, H. (1995) The Knowledge-Creating Company: How Japanese Companies Create the Dynamics of Innovation. Oxford University Press, New York.

[27] Nonaka, I. (1994) A Dynamic Theory of Organizational Knowledge Creation. Organization Science, 5, 14-37. $\underline{\text { https://doi.org/10.1287/orsc.5.1.14 }}$

[28] Chiocchio, F., Messikomer, C. and Dagenais, C. (2014) Knowledge Management in the Project Context: What It Means for HR Projects. In: Klimoski, R.J., Dugan, B., Messikomer, C. and Chiocchio, F., Eds., Advancing Human Resource Project Management, Pfeiffer \& Co, Singapore, 467-488.

https://doi.org/10.1002/9781118915912.ch17

[29] Anbari, F.T., Carayannis, E.G. and Voetsch, R.J. (2008) Post-Project Reviews as a Key Project Management Competence. Technovation, 28, 633-643. https://doi.org/10.1016/j.technovation.2007.12.001

[30] Kotnour, T. and Vergopia, C. (2005) Learning-Based Project Reviews: Observations and Lessons Learned from the Kennedy Space Center. Engineering Management Journa, 17, 30-38. https://doi.org/10.1080/10429247.2005.11431670

[31] Söderlund, J. (2005) Developing Project Competence: Empirical Regularities in Competitive Project Operations. International Journal of Innovation Management, 9, 451-480. https://doi.org/10.1142/S1363919605001344

[32] Prencipe, A. and Tell, F. (2001) Inter-Project Learning: Processes and Outcomes of Knowledge Codification in Project-Based Firms. Research Policy, 30, 1373-1394. https://doi.org/10.1016/S0048-7333(01)00157-3

[33] Newell, S. and Edelman, L.F. (2008) Developing a Dynamic Project Learning and Cross-Project Learning Capability: Synthesizing Two Perspectives. Information Systems Journal, 18, 567-591. https://doi.org/10.1111/j.1365-2575.2007.00242.x

[34] Carlile, P.R. and Rebentisch, E.S. (2003) Into the Black Box: The Knowledge Transformation Cycle. IEEE Engineering Management Review, 31, 67-80. 
https://doi.org/10.1109/EMR.2003.24940

[35] Kasi, V., Keil, M., Mathiassen, L. and Pedersen, K. (2008) The Post Mortem Paradox: A Delphi Study of IT Specialist Perceptions. European Journal of Information Systems, 17, 62-78. https://doi.org/10.1057/palgrave.ejis.3000727

[36] Söderlund, J., Vaagaasar, A.L. and Andersen, E.S. (2008) Relating, Reflecting and Routinizing: Developing Project Competence in Cooperation with Others. International Journal of Project Management, 26, 517-526. https://doi.org/10.1016/j.ijproman.2008.06.002

[37] Williams, K.E. and Kotnour, T.G. (1993) An Electronic Performance Support System for Organizational Learning. Computers \& Industrial Engineering, 25, 93-97, https://doi.org/10.1016/0360-8352(93)90229-Q

[38] Levitt, B. and March, J. (1988) Organizational Learning. Annual Review of Sociology, 14, 319-338. https://doi.org/10.1146/annurev.so.14.080188.001535

[39] Senge, P.M. (1990) The Fifth Discipline: The Art and Practice of the Learning Organization. Doubleday Dell, New York.

[40] Zollo, M. and Winter, S.G. (2002) Deliberate Learning and the Evolution of Dynamic Capabilities. Organization Science, 13, 339-351.

https://doi.org/10.1287/orsc.13.3.339.2780

[41] Schon, D.A. (1983) The Reflective Practitioner: How Professionals Think in Action. Basic Book, New York.

[42] Argyris, C. and Schön, D.A. (1978) Organisational Learning: A Theory of Action Perspective. Addison-Wesley, Reading, MA.

[43] Swan, J. et al. (1999) Knowledge Management and Innovation: Networks and Networking. Journal of Knowledge Management, 3, 262-275.

https://doi.org/10.1108/13673279910304014

[44] DeFillippi, R.J. (2001) Introduction: Project-Based Learning, Reflective Practices and Learning Outcomes. Management Learning, 32, 5-10. https://doi.org/10.1177/1350507601321001

[45] Creswell, J.W. (2009) Research Design: Qualitative, Quantitative and Mixed Methods Approaches. 3rd Edition, Sage Publications Inc, London.

[46] Saunders, M., Lewis, P. and Thornhill, A. (2015) Understanding Research Philosophies and Approaches. Pearson Education, Harlow.

[47] Guribie, F.L., Akubah, J.T., Callistus, T. and Victor, A.B.K. (2021) Demand for Green Building in Ghana: A Conceptual Modeling and Empirical Study of the Impediments. Construction Innovation.

[48] Tengan, C., Aigbavboa, C.O., Guribie, F. and Annor-Asubonteng, J. (2019) Analysis of the Outcome Features of Effective Monitoring and Evaluation in Construction Project Delivery. Journal of Engineering, Design and Technology, 17, 1192-1201. https://doi.org/10.1108/JEDT-03-2019-0076

[49] Norusis, M.J. (2011) IBM SPSS Statistics 19. Guide to Data Analysis. Addison Wesley, Boston.

[50] Chou, Y.M., Polansky, A.M. and Mason, R.L. (1998) Transforming Non-Normal Data to Normality in Statistical Process Control. Journal of Quality Technology, 30, 133-141. https://doi.org/10.1080/00224065.1998.11979832

[51] Huang, C.H. and Huang, I.C. (2009) The Moderating Effect of Co-Workers' Reactions on Social Ties and Knowledge Sharing in Work Teams. International Journal of Learning and Intellectual Capital, 6, 156-169. https://doi.org/10.1504/IJLIC.2009.021725 